\title{
Dual Polarization Stacked Microstrip Patch Antenna Array With Very Low Cross-
} Polarization

\author{
Granholm, Johan; Woelders, Kim
}

Published in:

I E E E Transactions on Antennas and Propagation

Link to article, DOI:

$10.1109 / 8.954928$

Publication date:

2001

Document Version

Publisher's PDF, also known as Version of record

Link back to DTU Orbit

Citation (APA):

Granholm, J., \& Woelders, K. (2001). Dual Polarization Stacked Microstrip Patch Antenna Array With Very Low Cross-Polarization. I E E E Transactions on Antennas and Propagation, 49(10), 1393 - 1402.

https://doi.org/10.1109/8.954928

\section{General rights}

Copyright and moral rights for the publications made accessible in the public portal are retained by the authors and/or other copyright owners and it is a condition of accessing publications that users recognise and abide by the legal requirements associated with these rights.

- Users may download and print one copy of any publication from the public portal for the purpose of private study or research.

- You may not further distribute the material or use it for any profit-making activity or commercial gain

- You may freely distribute the URL identifying the publication in the public portal

If you believe that this document breaches copyright please contact us providing details, and we will remove access to the work immediately and investigate your claim 


\title{
Dual Polarization Stacked Microstrip Patch Antenna Array With Very Low Cross-Polarization
}

\author{
Johan Granholm, Member, IEEE, and Kim Woelders
}

\begin{abstract}
This paper describes the development and performance of a wideband dual linear polarization microstrip antenna array used in the Danish high-resolution airborne multifrequency polarimetric synthetic aperture radar, EMISAR. The antenna was designed for an operating frequency of $1.25 \mathrm{GHz} \pm 50 \mathrm{MHz}$ and was built as an array of $8 \times 2$ probe-fed stacked microstrip patches. The feeding network is constructed in microstrip and is capable of handling $6 \mathrm{~kW}$ of peak input-power at an altitude of $45000 \mathrm{ft}$ (unpressurized). The impedance bandwidth (return-loss better than $-14 \mathrm{~dB}$ ) of the antenna is $10 \%$, the isolation between the horizontal and the vertical ports of the array is $50 \mathrm{~dB}$ and the cross-polarization suppression is $40 \mathrm{~dB}$. A new design principle for simultaneously achieving very low cross-polarization and low side lobes in dual linear polarization antenna arrays has been applied.
\end{abstract}

Index Terms-Antenna arrays, dual polarization antennas.

\section{INTRODUCTION}

A MULTIFREQUENCY polarimetric synthetic aperture radar (SAR) has been developed for high-resolution airborne remote sensing applications at the Department of Electromagnetic Systems (EMI), Technical University of Denmark [1]. This system, EMISAR, has been flown intensively since 1993 (C-band) and 1995 (L- and C-band) [2], [3]. The C- and L-band SAR systems were designed for simultaneous operation on antennas steered to zero Doppler, but the pod installation on the aircraft carrying the SAR (a Gulfstream G-3 jet of the Royal Danish Air Force) only permits one three-axis stabilized antenna at a time. Consequently, the L-band antenna was designed to be interchangeable with the C-band antenna, allowing the system to be configured on the ground for either C-band or L-band operation. The later addition of flush mounted antennas for C-band interferometry [4] made simultaneous dual frequency operation possible, with C-band operated in squint mode and the L-band system in zero Doppler mode. This paper describes the antenna that was developed for the polarimetric L-band system.

\section{ARRAy GeOMEtry, MeChaniCAL AND ElECtRICAL REQUIREMENTS}

The physical size of the L-band antenna array was limited by the available space in the existing aircraft pod, $1.3 \times 0.31 \times$ $0.15 \mathrm{~m}(\mathrm{~L} \times \mathrm{H} \times \mathrm{D})$. This aperture size supports an array with $8 \times 2$ elements, spaced $\approx 0.7 \lambda_{0}$ apart. The bandwidth required

Manuscript received October 5, 1999; revised February 16, 2001.

The authors are with the Danish Center for Remote Sensing, Department of Electromagnetic Systems, Technical University of Denmark, DK-2800 Lyngby, Denmark (e-mail: jg@oersted.dtu.dk).

Publisher Item Identifier S 0018-926X(01)07653-0. of the L-band SAR was $100 \mathrm{MHz}$, to obtain a range resolution of $2 \mathrm{~m}$ with low range sidelobes. The operating frequency was chosen to be 1.2 to $1.3 \mathrm{GHz}$ to comply with international frequency allocation regulations.

Present polarimetric SAR applications do not require cross-polarization suppression in the processed image better than $30 \mathrm{~dB}$ [5]. If, however, an antenna with cross-polarization suppression of e.g., $20 \mathrm{~dB}$ is used in a polarimetric SAR system, it is necessary in the SAR processing to correct for the antenna cross-polarization. This correction can potentially be done using distributed targets in the images [6]. A SAR scene cannot generally be expected to contain distributed targets suitable for such polarization calibration. It was, therefore, a requirement for the design described here that the cross-polarization suppression in the L-band array should be at least $30 \mathrm{~dB}$.

Further specifications on the antenna array were given implicitly in terms of the maximum allowed azimuth- and left/right ambiguity of the SAR system, and also multipath suppression due to aircraft wing reflections was considered [7]. The power handling requirement was $6 \mathrm{~kW}$ peak input power at $45000 \mathrm{ft}$ altitude, unpressurized. In principle, the elevation pattern of the array was desired to approximate a modified cosecant-squared pattern [8], but this requirement cannot be fulfilled by an array of this small electrical size - allowing only two elements to be used in the elevation dimension. The specifications are summarized in Table I.

\section{The RAdiating Element (SELECTION OF RAdiator AND FEEDING ARRANGEMENT)}

Several radiating element candidates exist which can comply with the above requirements. In array applications it is typically necessary to use elements that can be spaced approximately $0.7 \lambda_{0}$ apart. The microstrip patch element meets this criteria. Besides the simple mechanical construction, allowing rapid in-house fabrication, microstrip patches are attractive in terms of their relatively high element directivity and their low profile and weight.

To achieve cross-polarization suppression on the order of $30 \mathrm{~dB}$ it is important to avoid uncontrolled radiation, e.g., from the feed network. This precludes the use of coplanar-fed and proximity-coupled patches. Aperture-coupled patches suffer from excessive back radiation, which can be prevented only using a stripline feeding network or some potentially complicated backing structure. Probe-fed patch elements can be fed using a simple unshielded microstrip feeding network located on the rear of the patch ground plane and, therefore, do not suffer from the above-mentioned disadvantages. Furthermore, if employing a partly empirical approach for the design of the 
TABLE I

L-BAND ANTENNA ARRAY SPECIFICATIONS

\begin{tabular}{l|l}
\hline Polarization & Dual linear, $\mathrm{H}$ and $\mathrm{V}$ \\
\hline Operating frequency & 1.2 to $1.3 \mathrm{GHz}$ \\
\hline Input impedance both ports & $50 \Omega$, return loss better than $-14 \mathrm{~dB}$ \\
\hline Cross-polarization suppression & Better than $30 \mathrm{~dB}$ \\
\hline Input power & $6 \mathrm{~kW} \mathrm{pk}_{1}, 180 \mathrm{~W}_{\mathrm{avg}}$ (unpressurized at $45,000 \mathrm{ft}$ altitude) \\
\hline Maximum overall size $(\mathrm{LxHxD})$ & $1.3 \mathrm{~m} \times 0.31 \mathrm{~m} \times 0.15 \mathrm{~m}$ \\
\hline Array configuration & $8 \times 2$ elements, organized as four $2 \times 2$ element panels \\
\hline
\end{tabular}

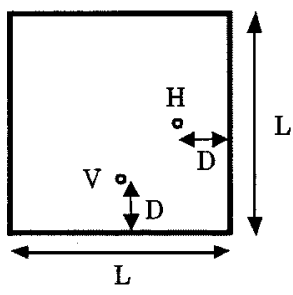

$\mathrm{L}=98.5 \mathrm{~mm}$

$\mathrm{D}=27.0 \mathrm{~mm}$

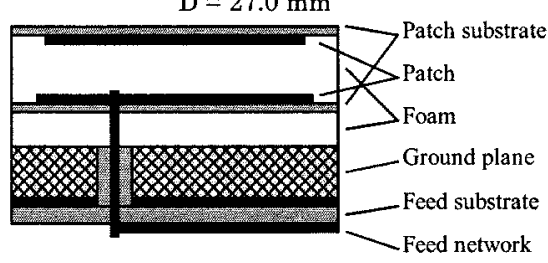

Fig. 1. Top view of the lower patch. Cross-section view of dual polarization probe-fed microstrip stacked patch antenna element.

radiating patch, the number of variables in a probe fed patch design (e.g., patch size, substrate thickness, feed-offset) are fewer than in an aperture-coupled patch and simpler to vary too. Because of the good performance obtained from the previously developed dual polarization C-band microstrip antenna array [9] it was decided, that the L-band antenna should also be constructed as a probe-fed microstrip patch array.

One major difference between the C-band and the L-band antenna arrays is the $8 \%$ relative bandwidth required at L-band compared to only $2 \%$ at $\mathrm{C}$-band. The $8 \%$ bandwidth requirement is quite large for a simple microstrip patch. After initial measurements on L-band microstrip patches it became evident, that a single microstrip patch could not obtain the required $8 \%$ impedance bandwidth (the bandwidth over which the antenna element can be matched to the feedline to some level, e.g., $S_{11}$ better than $-14 \mathrm{~dB}$ ). In order to increase the impedance bandwidth of the single patch a parasitic element was added, and in this way a broadband "stagger-tuned" (dual resonance) patch was obtained. Parasitic elements may be added to microstrip patches in various ways. In this application the obvious choice was to employ a stacked-patch solution, see Fig. 1.

The lower patch is driven by the probe(s) and the upper patch is the passive parasitic element. Due to the single-frequency dual linear polarization requirement, the stacked microstrip patch is constructed as a pair of quadratic patches. When the patch is fed

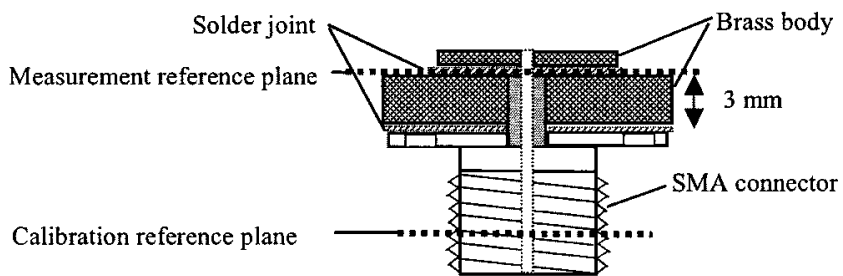

Fig. 2. Definition of calibration reference plane and details of offset short used.

on the center lines as shown in Fig. 1 the resonant frequencies are identical for the $\mathrm{H}$ and $\mathrm{V}$ polarizations.

\section{Design of the Stacked Patch Radiating Element}

Several stacked microstrip patch antenna designs have been reported in the literature, the majority being empirically based. Parametric studies have been reported [10], [11], aimed at determining the variables in single polarization stacked patch configurations (i.e., patch side length, substrate thickness and feedoffset) to meet specific requirements, but the different "optimum stacked patch designs" given in the literature do not agree very well. The amount of coupling between the ports of the basic radiating element (i.e., the scattering parameter $\mathrm{S}_{21}$ ) will affect the cross-polarization performance of the overall array. A dual-polarization array with low $S_{21}$, requires that $S_{21}$ of the individual element is reasonably low (preferably $\leq-25 \mathrm{~dB}$ ). In the literature information on $S_{21}$ of dual polarization stacked patches is very scarce; the issue of achieving low $S_{21}$ in a dual polarization stacked microstrip patch elements seems not to have been addressed at all.

A series of 45 dual polarization probe-fed stacked microstrip patches having different side lengths, substrate thickness and probe feeding point offsets were fabricated and measured in order to empirically develop the basic radiating element to be used in the L-band array. The patches were mounted on a 3-mm-thick groundplane as shown in Fig. 1. The patches were fed using a SMA connector having an extended PTFE dielectric of $4.1 \mathrm{~mm}$ in diameter and inner conductor diameter of $1.3-\mathrm{mm}$, thus, forming a $50 \Omega$ coaxial transmission line through the groundplane and the feeding probe.

Two-port $S$-parameters of all patches were measured on a vector network analyzer (NWA). The measurement reference plane at both ports was moved from the connector (i.e., the calibration reference plane) to the patch groundplane, using the 

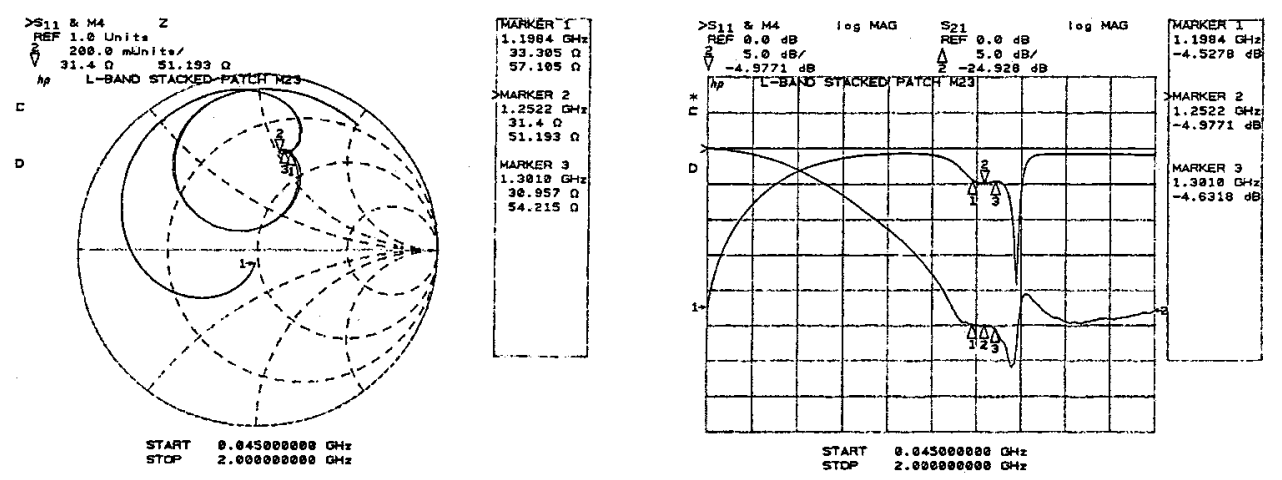

Fig. 3. Measured impedance of selected stacked patch element and the transmission between the ports.

"port extension" feature of the NWA. For this purpose an offset short, as shown in Fig. 2, was used (a SMA-connector forms a $50 \Omega$ transmission line through a $3 \mathrm{~mm}$ thick groundplane and is shorted at the end of the transmission line).

The starting point in the measurement series was to use a single patch being resonant at $1.25 \mathrm{GHz}$. The resonant frequency is in this context defined as the frequency where the real-part of the patch input impedance achieves its maximum. In order to identify the stacked patch element with the largest impedance bandwidth, a Smith chart was used to display the impedance trace over the frequency range 1.2 to $1.3 \mathrm{GHz}$. The smaller the area encircled by the impedance trace, the more constant the input impedance of the element, thus, the easier to match the element to $50 \Omega$. In addition to observing the input impedance $\left(S_{11}\right.$ and $\left.S_{22}\right)$, the magnitude of $S_{21}$ was used as a figure of merit.

The stacked patch configuration finally selected had the following dimensions: Lower patch $98.5 \times 98.5 \mathrm{~mm}$, feeding point $27 \mathrm{~mm}$ from the edges, upper patch $85 \times 85 \mathrm{~mm}$, lower dielectric $8 \mathrm{~mm}$ Rohacell $31 \mathrm{HF}$ foam $\left(\varepsilon_{r}=1.08, \tan \delta=\right.$ $0.0001 @ 2 \mathrm{GHz}$ ), upper dielectric $16 \mathrm{~mm}$ Rohacell 31HF foam, both patches etched on $0.381 \mathrm{~mm} \mathrm{RT/duroid} 5870\left(\varepsilon_{r}=2.33\right.$, $\tan \delta=0.0012 @ 10 \mathrm{GHz}$ ), lower patch facing upwards (to facilitate the probe-patch solder-joint), upper patch facing downwards (i.e., inverted), thus, making the upper dielectric act as a protective cover. The layers were assembled using $0.1 \mathrm{~mm}$ thick $3 \mathrm{M}$ type 665 adhesive film. The measured input reflection coefficients $S_{11}$ and $S_{22}$ (M4 on plots) and the transmission $\mathrm{S}_{21}$ between the ports of the element is shown in Fig. 3 (the reference impedance is $50 \Omega$ ).

The input impedance is reasonably constant from 1.2 to $1.3 \mathrm{GHz}$. Over this frequency range the real part of the impedance varies between $29 \Omega$ to $33 \Omega$ and the imaginary part from $51 \Omega$ to $57 \Omega$. The input reflection coefficient $\left(\mathrm{S}_{11}\right.$ and $\mathrm{S}_{22}$ ) of the unmatched element is $\approx-5 \mathrm{~dB}$. The transmission between the ports of the element $\left(\mathrm{S}_{21}\right)$ is almost constant at $-25 \mathrm{~dB}$.

SAR system considerations specified an element spacing of $167 \mathrm{~mm}$ in the azimuth direction and $135 \mathrm{~mm}$ in the elevation direction $\left(0.70 \lambda_{0}\right.$ and $\left.0.56 \lambda_{0}\right)$ [12]. In order to assess the level of mutual coupling, a $2 \times 2$ element array with these element spacings was built. The mutual coupling between different elements and polarizations in the $2 \times 2$ element group was measured. It was found that the strongest mutual coupling in the $2 \times 2$ element group (of unmatched elements) appeared in the E-plane for the $\mathrm{V}$ polarization. The level was approximately $-17 \mathrm{~dB}$. For the H-polarization the E-plane coupling was approximately $-20 \mathrm{~dB}$. The cross-polarization coupling between adjacent elements was below $-25 \mathrm{~dB}$. Due to these fairly low values, the effect of mutual coupling was not taken into account in the design of the array.

The radiation pattern of the selected stacked patch element was measured in the spherical near-field test facility at EMI [13]. The reference-element radiation pattern, shown in Fig. 4, was used for the pattern calculations during the subsequent design of the $8 \times 2$ element array.

The pattern is clearly asymmetrical due to the probe feeding. Within the mainlobe the cross-polarization level is on the order of $-25 \mathrm{~dB}$. The peak directivity is $9 \mathrm{dBi}$. The copolar radiation pattern was found to be practically constant over the 1.2 to $1.3 \mathrm{GHz}$ frequency range.

It was desired to match the individual elements to a $50 \Omega$ level and combine the elements into groups at the $50 \Omega$ level. An impedance matching network was designed in microstrip on a $1.52 \mathrm{~mm}$ thick Rogers RO3003 dielectric substrate $\left(\varepsilon_{r}=3.00\right.$, $\tan \delta=0.0013 @ 10 \mathrm{GHz}$ ) to match the patch to the $50 \Omega$ level over the 1.2 to $1.3 \mathrm{GHz}$ frequency range. In Fig. 5(a) the measured $S$-parameters are shown for the dual polarization patch including the two matching networks. The patch matching network layout (one connected to each feeding probe) is shown in Fig. 5(b); the position of the probe is indicated by a small dot.

The return-loss (upper graph) is below $-28 \mathrm{~dB}$ over the frequency range 1.2 to $1.3 \mathrm{GHz}$ but $\mathrm{S}_{21}$ (lower graph) has now increased from $-25 \mathrm{~dB}$ (for the "naked" element) to $-23 \mathrm{~dB}$ due to the improved matching.

\section{V. "Prior" Cross-Polarization SupPression TECHNiQuE}

An array constructed of identically oriented and -fed dual polarization antenna elements has the same cross-polarization level as the individual elements. This level can be improved by using pairwise mirrored elements as shown in Fig. 6(a) and feeding the $\mathrm{H}$ ports of two adjacent mirrored patches $180^{\circ}$ out of phase, while feeding the $\mathrm{V}$ ports in phase, as was done in the dual polarization antenna for the C-band SAR [9]. 

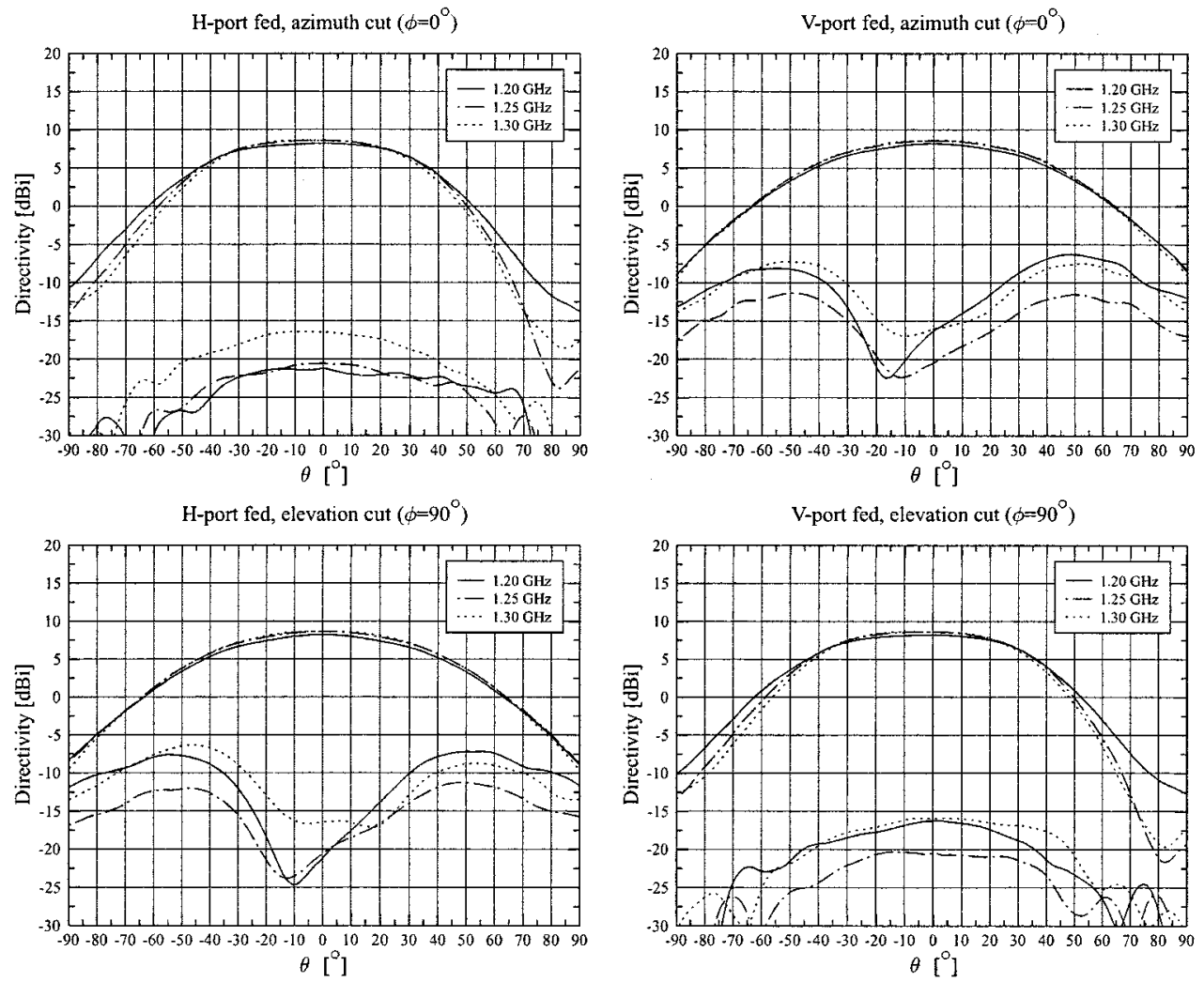

Fig. 4. Measured co- and cross-polarization radiation pattern for the stacked microstrip patch $(f=1.20,1.25$, and $1.30 \mathrm{GHz})$.

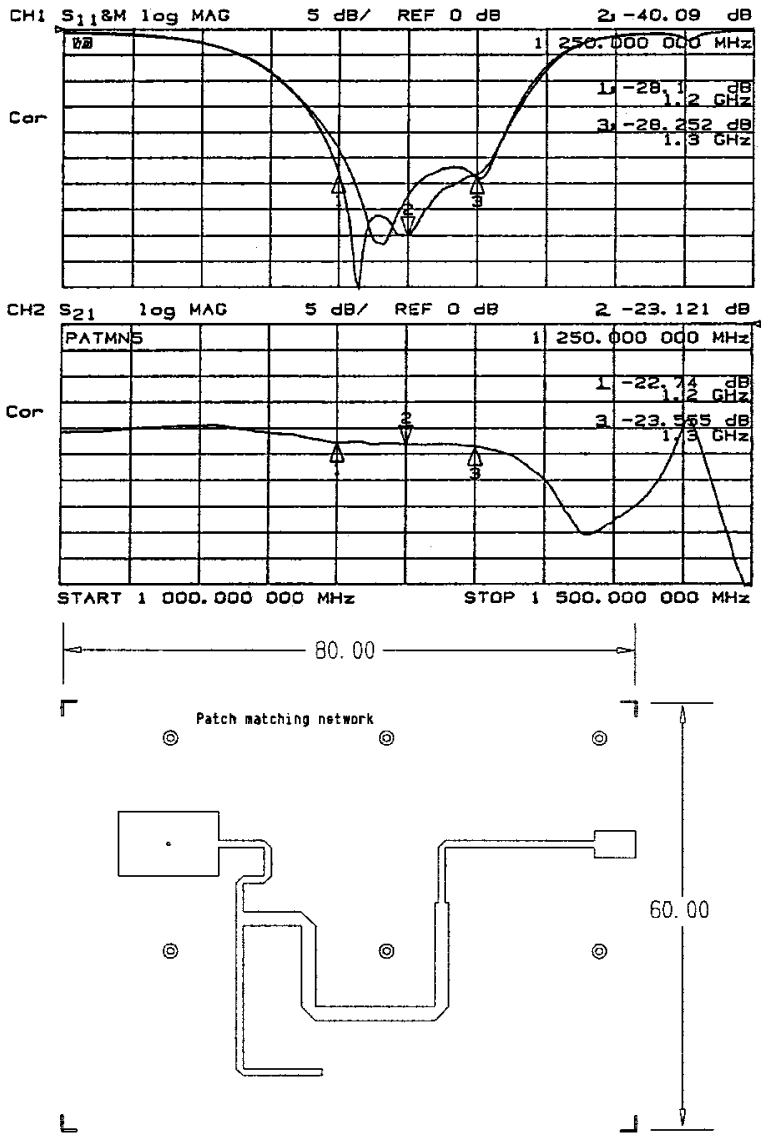

Fig. 5. Measured $S$-parameters for the dual polarization patch including patch matching networks and layout of microstrip matching network.

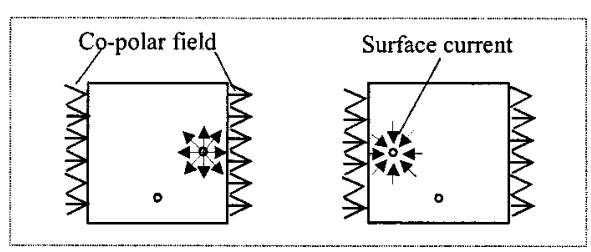

(a)

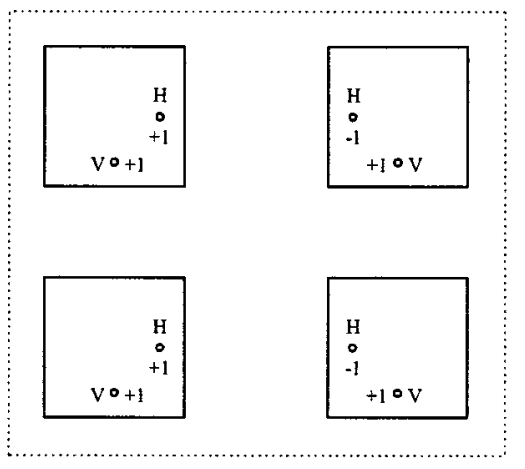

(b)

Fig. 6. (a) Two-mirrored element pair. (b) Four-element dual polarization antenna group based on the two-mirrored element pair.

In the figure " +1 " and " -1 " are the complex element excitations. In Fig. 6(a) the surface currents on the patches near the driven probes and the copolar electrical fields are indicated for feeding at the H-ports. The copolar fields from the patches will add in phase toward boresight. The cross-polarization will be significantly improved in the elevation plane. When fed on the 

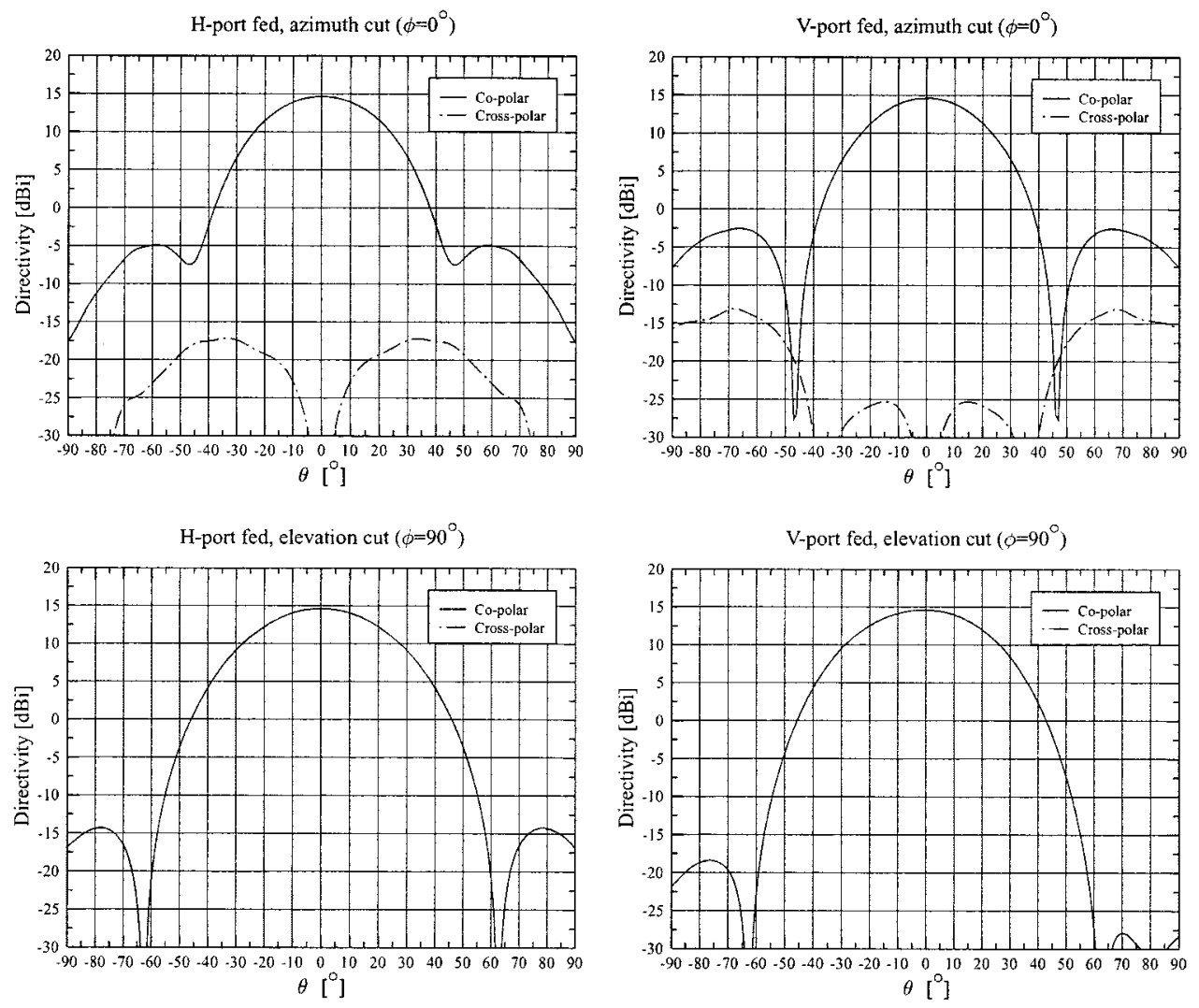

Fig. 7. Calculated radiation pattern of four-element group using prior cross-polarization suppression technique.

H-ports, the cross-polarization of the two-element pair in the elevation plane consists to a first approximation of the contribution from the probes and from the signals that leak through the elements to the V-ports (due to nonzero $S_{21}$ of the individual elements). Both cross-polar contributions will cancel because the two H-ports are fed $180^{\circ}$ out of phase. When fed on the V-ports, the cross-polarization of the two-mirrored element pair in the elevation plane consists primarily of the contributions from the signals that leak through the elements to the H-ports (the V-probe fields are copolar in the elevation plane). These cross-polarization field contributions will cancel due to the opposite locations of the H-port feeding points.

With proper design of the feeding network for the two-mirrored element pair, the transmission $S_{21}$ between the input ports of the two-mirrored element pair vanishes, regardless of the value of $S_{21}$ of the individual element. The mirrored pair feeding technique has been used to reduce $S_{21}$ of coplanar-fed dual polarization microstrip patch arrays, [14].

The calculated radiation pattern of a four-element group constructed of two-mirrored element pairs [Fig. 6(b)] is shown in Fig. 7. The element spacing in all $2 \times 2$ element groups considered below is $0.70 \lambda_{0} \times 0.56 \lambda_{0}$.

The cross-polarization of this group is significantly improved compared to that of the individual element (the radiation pattern shown in Fig. 4). Note that this feeding method causes a "missing null" (at $\theta= \pm 46^{\circ}$ ) in the azimuth plane radiation pattern for the horizontal polarization of the four-element group constructed as two mirrored element pairs. This missing null will result in grating lobes in arrays employing the in Fig. 6(a) shown two-mirrored element pairs [15], [16]. In e.g., the dual polarization C-band array [9], using these two-mirrored element pairs, grating lobes occurred in the azimuth plane for the H-polarization for $\theta= \pm 42^{\circ}$ only $20 \mathrm{~dB}$ below the main beam peak (the element spacing used in this array was $0.75 \lambda_{0} \times 0.70 \lambda_{0}$ ). The measured radiation pattern of the $\mathrm{C}$-band array is shown in Fig. 8.

For the $\mathrm{V}$ polarization a pair of grating lobes occurred in the azimuth plane at the same angles, $23 \mathrm{~dB}$ below the main beam peak. These grating lobes are an inherent disadvantage of the "mirrored pair" feeding technique. Thus, the penalty paid for the improved cross-polarization suppression and for the improved $\mathrm{S}_{21}$ of the two-mirrored element pairs is the formation of the grating lobes.

\section{New CRoss-Polarization Suppression TeChniQue}

A new design principle which preserves the advantages of the "mirrored pair" feeding technique (improved cross-polarization suppression and low $\mathrm{S}_{21}$ of the array), while avoiding the inherent disadvantages (grating lobes) is described in [15], [16]. One property of this new principle is to restore the missing nulls of the two-mirrored element pair of Fig. 6(a), by arranging the elements and the feeding of the elements in a four-element group as shown in Fig. 9.

The four-element group consists of two two-mirrored element pairs (upper and lower). The upper element pair is as shown in Fig. 6(b), whereas the lower element pair has the individual elements swapped. The horizontal polarization excitations of the 

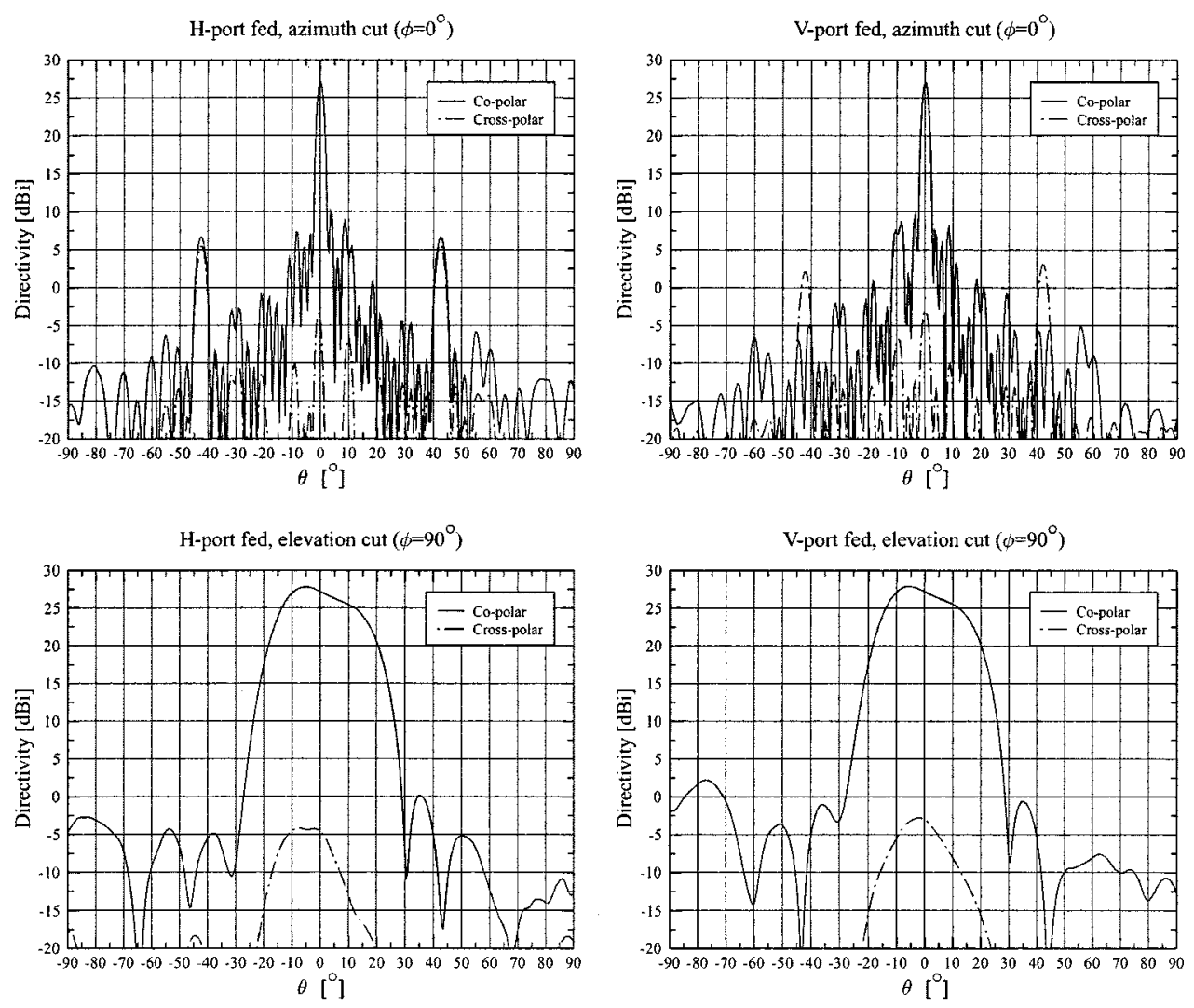

Fig. 8. Measured radiation pattern of $32 \times 7$ element C-band microstrip patch array.

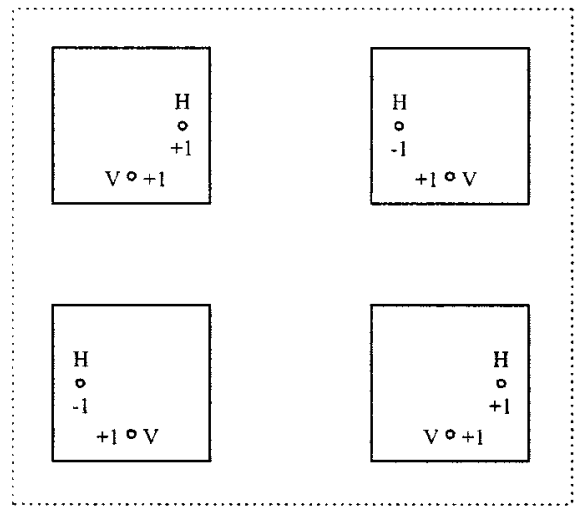

Fig. 9. Four-element antenna group using new cross-polarization suppression technique.

elements in the upper and the lower element pairs must therefore be in anti-phase (indicated by " +1 " and " -1 ") to let the copolar signals from the elements add in phase toward boresight. The vertical polarization excitations are all in phase. Each of the two pairs (upper and lower) will feature the same good cross-polarization properties as the two-mirrored element pair shown in Fig. 6(a), and each of the pairs will also have very low $S_{21}$. The four-element group will restore the missing nulls of the horizontal polarization in the azimuth-plane radiation pattern, [16]. The calculated radiation pattern of the new four-element group is shown in Fig. 10.
The cross-polarization vanishes in the elevation plane for both the $\mathrm{H}-$ and the V-polarization. In the azimuth plane the cross-polarization is significantly suppressed, particularly for the H-polarization. Note that the nulls in the $\mathrm{H}$-polarization azimuth plane are restored compared to Fig. 7.

\section{The Microstrip FEEDING NETWORK}

The $8 \times 2$ element L-band antenna was designed using the new principle. To implement the element excitations, a feeding network was designed in microstrip (on 1.52-mm-thick Rogers RO3003 dielectric substrate). The microstrip network was glued onto the nonradiating side of a silver-plated aluminum groundplane using an electrically conductive (silver-filled) epoxy-based adhesive film (Ablefilm 5025E supplied by Ablestik Laboratories, Inc.). Fig. 11 shows the layout of one $2 \times 2$ element L-band panel, including the outline of the patches.

The elements within a $2 \times 2$ element panel have uniform excitations. Note that the groundplane does not extend much beyond the patch edges.

The network comprises two-way $-3-\mathrm{dB} / 0^{\circ}$ Wilkinson power dividers to feed the $\mathrm{V}$ ports (with $100 \Omega$ high-power chip resistors glued to the 3 -mm aluminum ground plane), and two-folded $-3-\mathrm{dB} / 180^{\circ}$ hybrids ("rat races") to feed the $\mathrm{H}$ ports. The networks were designed and tested individually before being integrated into the final layout. The Wilkinson divider achieved 

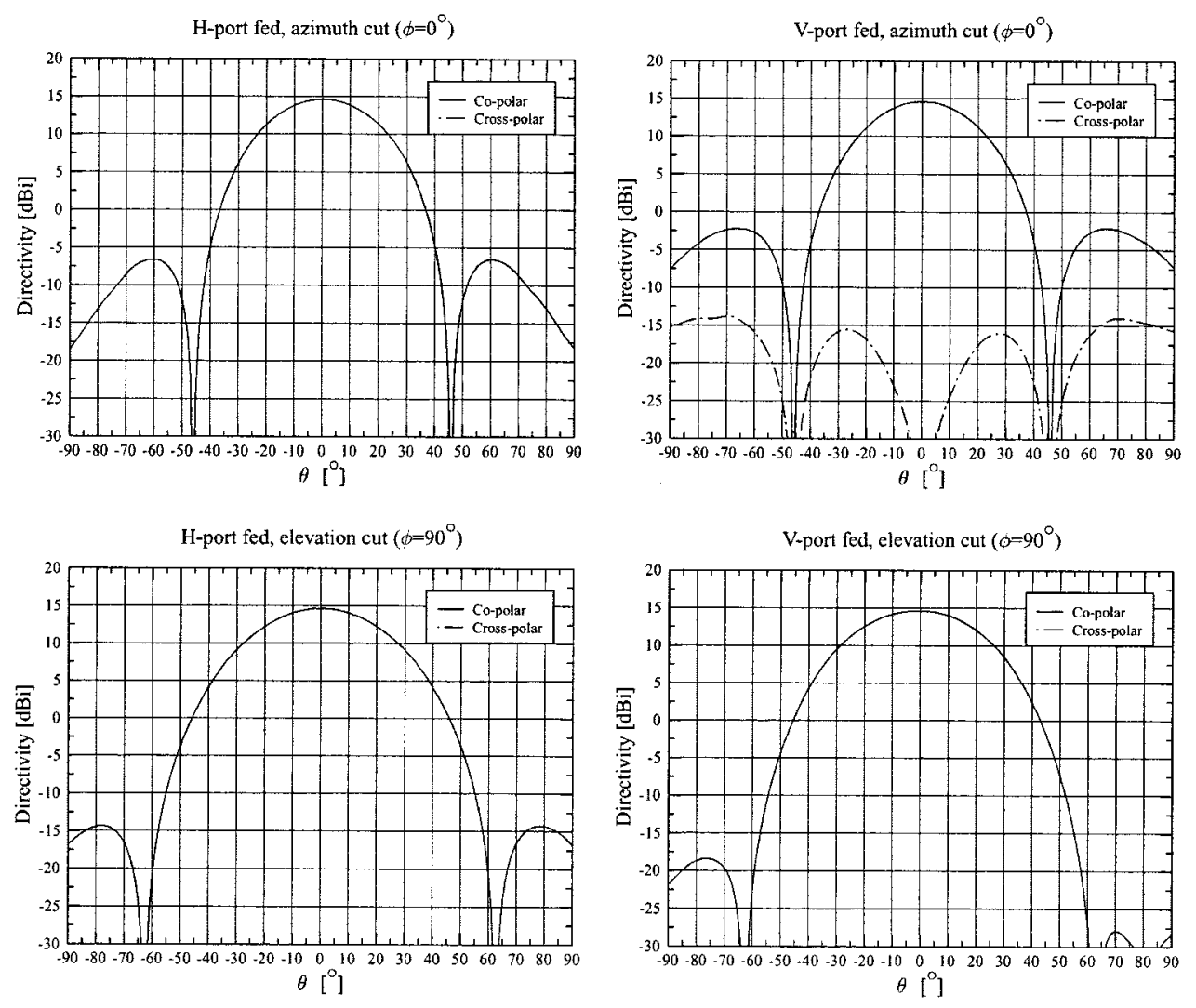

Fig. 10. Calculated radiation pattern of four-element group using new cross-polarization suppression technique.

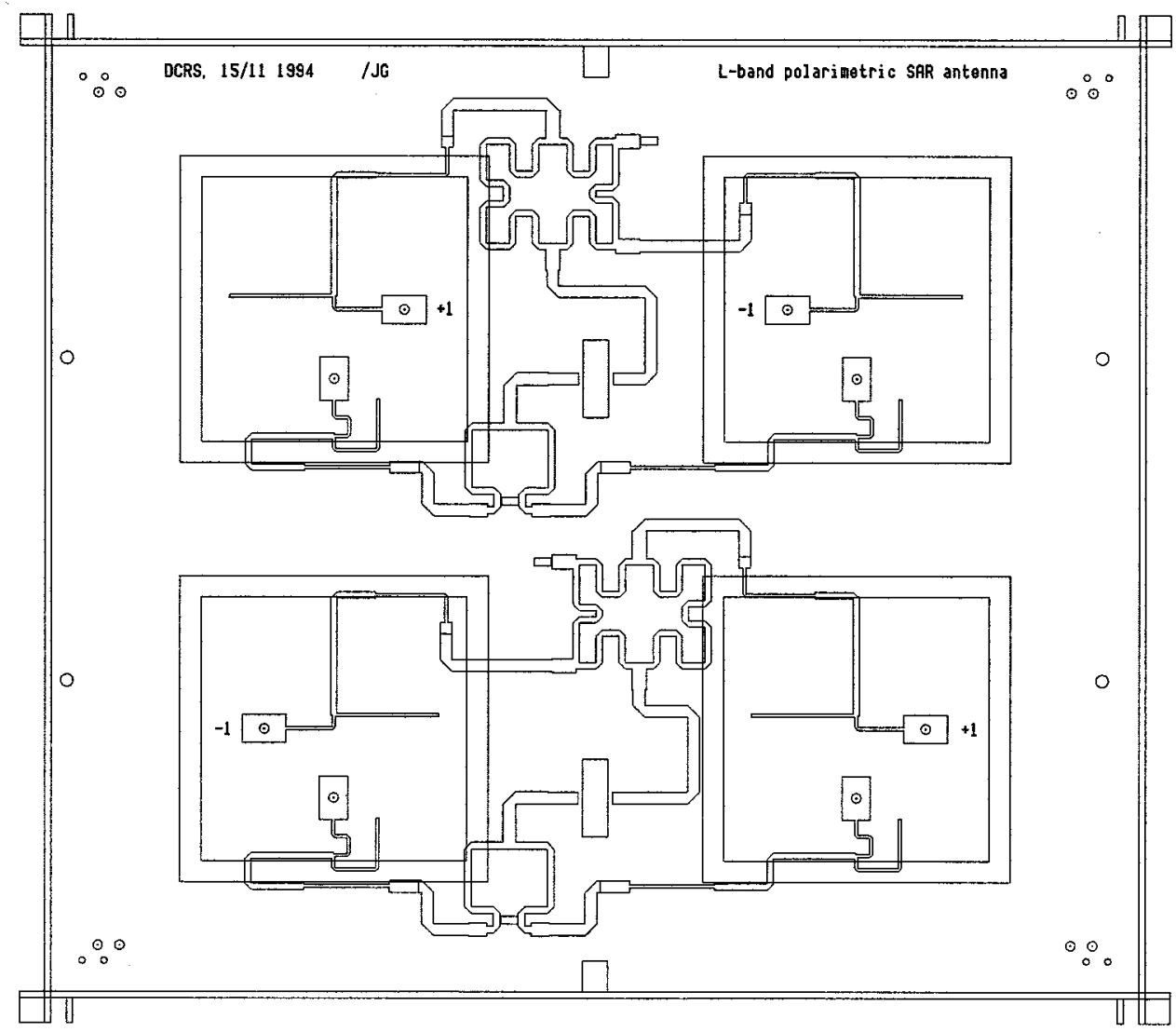

Fig. 11. Microstrip layout of $2 \times 2$ element dual polarization L-band antenna panel (PCB size: $341 \mathrm{~mm} \times 304 \mathrm{~mm}$ ). 


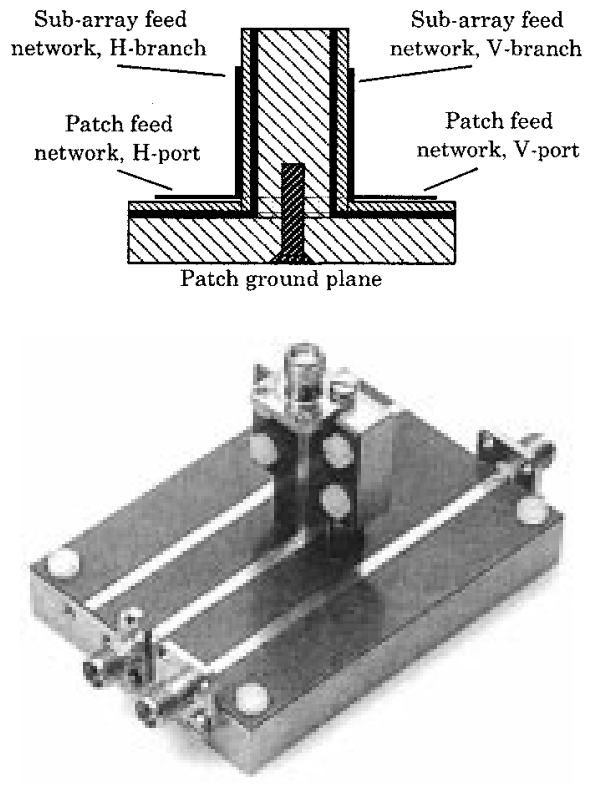

Fig. 12. Vertical microstrip $50 \Omega$ E-plane bend, cross section and one bend prototype.

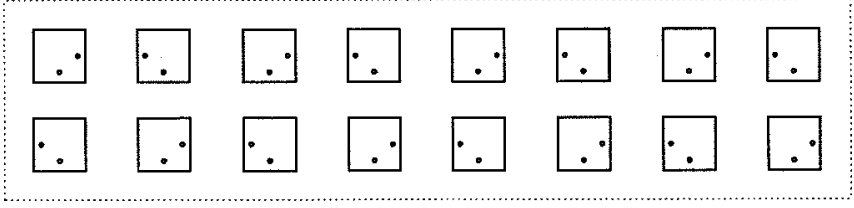

Fig. 13. Patch configuration for $8 \times 2$ element dual polarization L-band array.

$-32 \mathrm{~dB}$-worst-case return-loss across the band and has an insertion loss below $0.07 \mathrm{~dB}$. The amplitude and phase imbalance of the rat-race between the $0^{\circ}$ and $180^{\circ}$ outputs across the $100-\mathrm{MHz}$ band of interest is below $\pm 0.07 \mathrm{~dB}$ and $\pm 2.5^{\circ}$ respectively. The return-loss over the $100-\mathrm{MHz}$ band for all ports of the rat-race is better than $-25 \mathrm{~dB}$, and the loss is below $0.15 \mathrm{~dB}$. In Fig. 11, the input lines from the Wilkinson dividers and the rat-races end near a rectangle. This rectangle represents the "footprint" of $90^{\circ}$ vertical microstrip E-plane bends, of the type shown in Fig. 12.

The vertical $50 \Omega$ microstrip E-plane bends, which were also used in the C-band array [9], have a return-loss better than $-30 \mathrm{~dB}$ up to $6 \mathrm{GHz}$. Tiny beryllium-copper "reinforcement angles" are soldered across the bends. The vertically located microstrip networks, dividing the power between the upper and lower two-element groups, are $-3 \mathrm{~dB} / 0^{\circ}$ Wilkinson splitters (the V-polarization divider is on one side of the vertically mounted groundplane, and the $\mathrm{H}$-polarization divider is on the other side).

To improve the SAR-system azimuth ambiguity the array is tapered slightly in the azimuth direction, [12]. The four $2 \times 2$ element panels are therefore fed with excitations $-8.8 \mathrm{~dB},-4.3 \mathrm{~dB},-4.3 \mathrm{~dB},-8.8 \mathrm{~dB}$, respectively. The network feeding the four panels is constructed in microstrip on $2.54 \mathrm{~mm}$ thick Rogers RT/duroid 6006 dielectric substrate $\left(\varepsilon_{r}=6.15, \tan \delta=0.0019 @ 10 \mathrm{GHz}\right)$. Identical circuits are used for the $\mathrm{H}$ - and the $\mathrm{V}$-polarization. The network is based on the "Gysel"-type $-3 \mathrm{~dB} / 0^{\circ}$ power dividers (with high-power $50 \Omega$ dumping-resistors connected directly to ground at the one end, thus easy to implement electrically and thermally very effectively heat-sinked), [17], [18]. To accommodate the $6 \mathrm{~kW}$ peak input power requirement at $45000 \mathrm{ft}$ altitude (unpressurized) the input connectors of the array power division network are of the HN-type, while the output connectors in the antenna all are of the N-type. Semi-rigid coaxial cables $\left(0.141^{\prime \prime}\right.$ outer diameter) connect the output from the array power division network to the four panels. The patch configuration for the $8 \times 2$ element dual polarization L-band array is shown in Fig. 13.

The calculated radiation pattern of the $8 \times 2$ element array is shown in Fig. 14.

Cross-polarization is almost absent for both polarizations in both the azimuth and the elevation plane. The peak directivity is $20 \mathrm{dBi}$. No grating lobes are seen. Note the presence of all nulls in the patterns and the very low cross-polarization level.

\section{Measured Array Performance}

The measured input reflection coefficients (upper graph) and the transmission between the H- and V-ports (lower graph) of the $8 \times 2$ element dual polarization L-band antenna are shown in Fig. 15.

It is seen that the $\mathrm{H}$ - and the V-polarization reflection coefficients (upper graph) are below $-14 \mathrm{~dB}$ over an $11 \%$ bandwidth. It should be mentioned, however, that the $\mathrm{H}$ - and V-port input reflection coefficient of the four-element groups were initially only on the order of $-13 \mathrm{~dB}$ and $-10 \mathrm{~dB}$, respectively. The degradation from the very good element match (shown in Fig. 5) is believed to be caused by the neglected mutual coupling effects. To improve the matching, the network shown in Fig. 5 was tuned by soldering small pieces of copper tape (identical for all elements) to two of the matching lines. The transmission between the $\mathrm{H}$ - and $\mathrm{V}$-ports is improved from $-23 \mathrm{~dB}$ for the individual microstrip patch element (see Fig. 5) to approximately $-50 \mathrm{~dB}$ for the array.

Fig. 16 shows the measured radiation pattern for the $8 \times 2$ element dual polarization L-band.

The measured peak directivity varies over the 1.2 to $1.3 \mathrm{GHz}$ frequency range from 18.8 to $19.5 \mathrm{dBi}$ for the $\mathrm{V}$ polarization and from 18.1 to $19.0 \mathrm{dBi}$ for the $\mathrm{H}$ polarization. The measured loss in the antenna array is $1.5 \mathrm{~dB}$; almost the same for the two polarizations. The cross-polarization level is on the order of -35 to $-40 \mathrm{~dB}$ in the azimuth plane and below $-40 \mathrm{~dB}$ in the elevation plane. The asymmetry in the azimuth plane of the horizontal polarization pattern is believed to be due to minor amplitude/phase unbalances in the feeding network. The measured pattern does not have the predicted nulls in elevation for $\theta= \pm 63^{\circ}$. The reason is that the ground plane for the real antenna only extends $0.15 \lambda_{0}$ beyond the edges of the patches, causing the radiation patterns for the upper and lower patches to be perturbated in opposite directions. This is also believed to be the reason for especially the cross-polarization fields in azimuth 

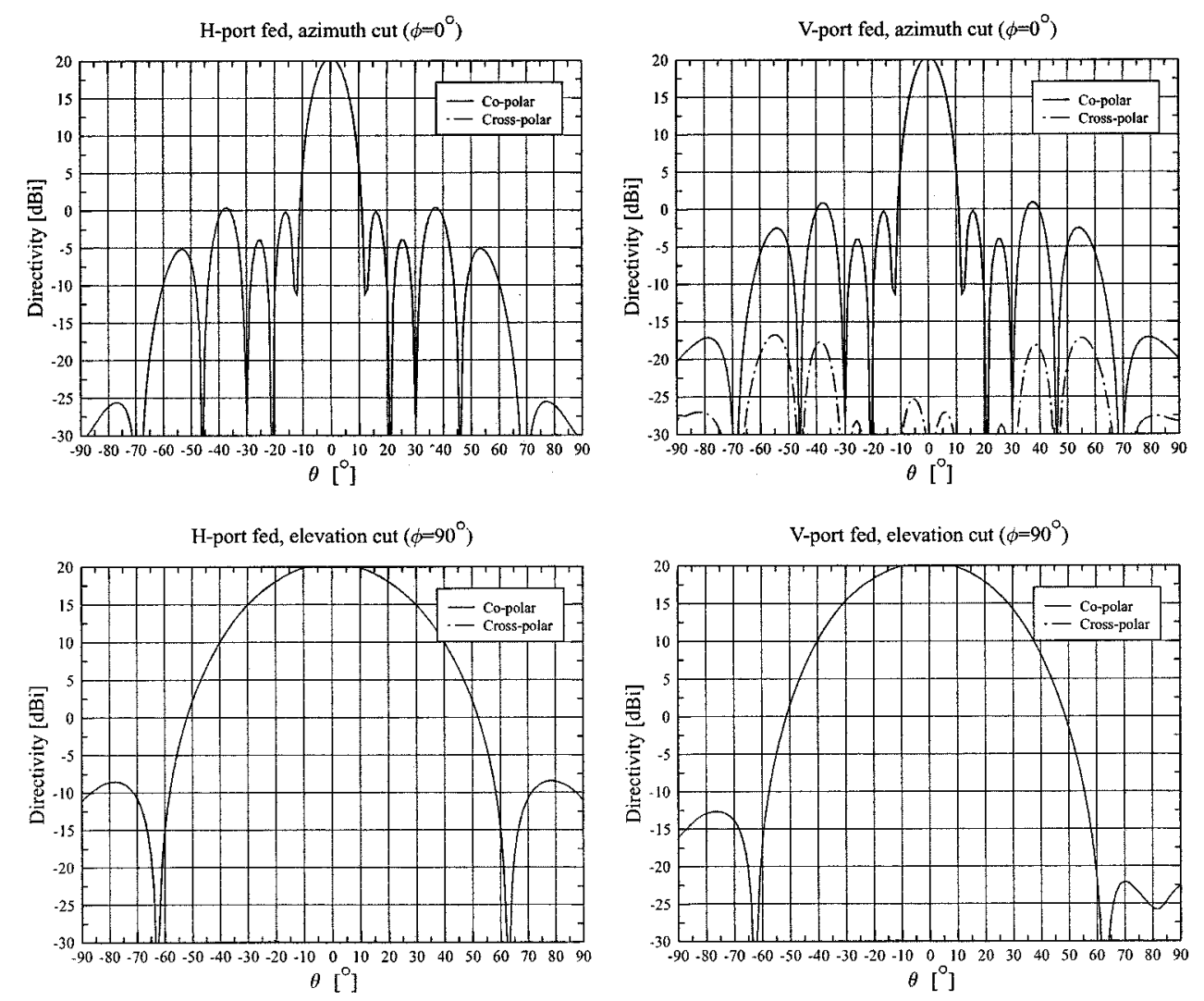

Fig. 14. Calculated radiation pattern of $8 \times 2$ element dual polarization L-band array.
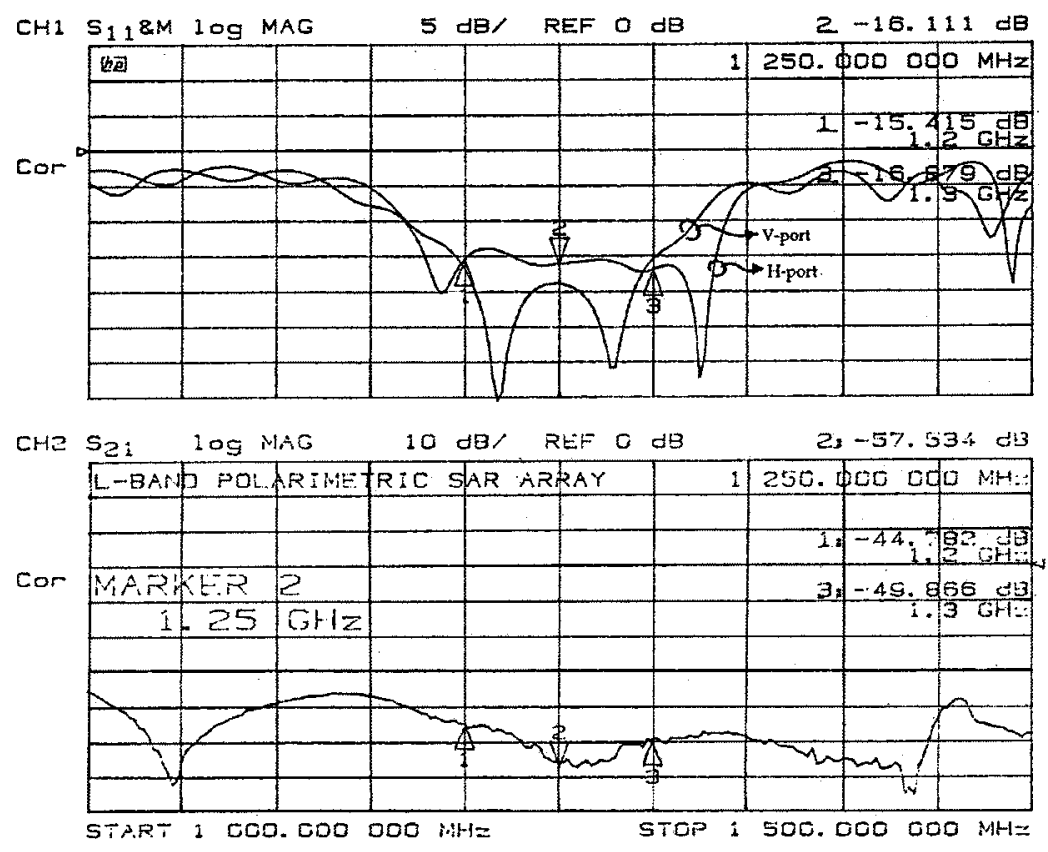

Fig. 15. Measured $S$-parameters of the $8 \times 2$ element dual polarization L-band array.

being somewhat higher than predicted. The array radiation outside the $\theta= \pm 90^{\circ}$ region (i.e., outside the forward region of the array) was suppressed more than $45 \mathrm{~dB}$, partly due to the use of probe-fed patches, partly because all the feeding networks were completely shielded.
The array has successfully been flown for 6 years as a part of the Danish high resolution multifrequency airborne SARsystem EMISAR and the mechanical construction has proved to sustain the repeated temperature cycles in the pod, from $+35^{\circ} \mathrm{C}$ at ground level to $-65^{\circ} \mathrm{C}$ at $41000 \mathrm{ft}$ altitude. 

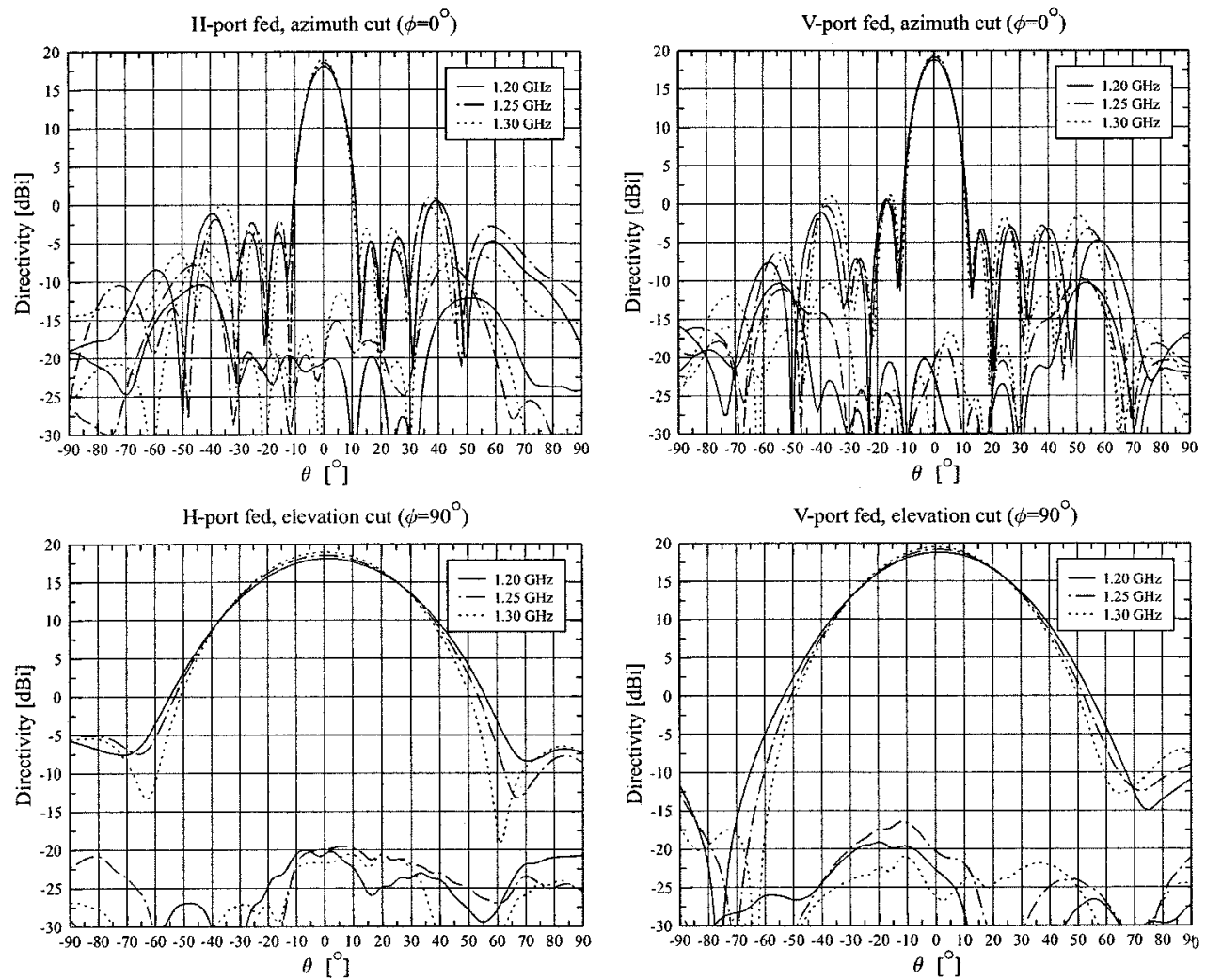

Fig. 16. Measured radiation pattern of the $8 \times 2$ element dual polarization L-band array.

\section{CONCLUSION}

The development and performance of an $8 \times 2$ element L-band dual linear polarization stacked wideband microstrip patch antenna array is described. The array design is based on a new cross-polarization suppression technique. Using this technique the cross-polarization level in the array is significantly suppressed compared to the cross-polarization level of the basic radiating element and no undesired sidelobes occur in the radiation pattern of the array. The combination of bandwidth and radiation pattern purity obtained for this array is believed to represent state-of-the-art in probe-fed microstrip antenna arrays.

\section{REFERENCES}

[1] E. L. Christensen, N. Skou, J. Dall, K. Woelders, J. H. Jørgensen, J. Granholm, and S. N. Madsen, "EMISAR: An absolutely calibrated polarimetric L- and C-band SAR," IEEE Trans. Geosci. Remote Sensing, vol. 36, pp. 1852-1865, Nov. 1998.

[2] E. L. Christensen, S. N. Madsen, J. Dall, N. Skou, J. H. Jørgensen, K. Woelders, A. Netterstrøm, J. Granholm, and M. Dich, "The Danish polarimetric SAR for remote sensing applications," in Proc. IGARSS' 94, Int. Geoscience Remote Sensing Symp., Pasadena, CA, Aug. 1994, pp. 1361-1364.

[3] N. Skou, J. Granholm, K. Woelders, J. Rohde, J. Dall, and E. L. Christensen, "A high resolution polarimetric L-band SAR-Design and first results," in IGARSS '95, 1995 Int. Geoscience Remote Sensing Symp., vol. III, Firenze, Italy, July 1995, pp. 1779-1782.

[4] S. N. Madsen, N. Skou, J. Granholm, K. Woelders, and E. L. Christensen, "A system for airborne SAR interferometry," Archiv für Elektronik und Überträgungstechnik; Int. J. Electron. Commun., vol. 50, no. 2, pp. 106-111, March 1996.

[5] P. C. Dubois, D. Evans, and J. van Zyl, "Approach to derivation of SIR-C science requirements for calibration," IEEE Trans. Geosci. Remote Sensing, vol. 30, pp. 1145-1149, Nov. 1992.

[6] J. D. Klein, "Calibration of complex polarimetric SAR, imagery using backscatter correlations," IEEE Trans. Aerosp. Electron. Syst., vol. 28, pp. 183-194, Jan. 1992.
[7] E. L. Christensen and M. Dich, "SAR antenna design for ambiguity and multipath suppression," in Proc. IGARSS '93, Int. Geosci. Remote Sensing Symp., vol. 2, Tokyo, Japan, Aug. 1993, pp. 784-787.

[8] S. N. Madsen, E. L. Christensen, N. Skou, and J. Dall, "The Danish SAR system: Design and initial tests," IEEE Trans. Geosci. Remote Sensing, vol. 29, pp. 417-426, May 1991.

[9] J. Granholm, K. Woelders, M. Dich, and E. L. Christensen, "Microstrip antenna for polarimetric C-band SAR," in 1994 IEEE Int. Symp. Antennas and Propagation, Seattle, WA, June 1994, pp. 1844-1847.

[10] T. M. Au and K. M. Luk, "Effect of parasitic element on the characteristics of microstrip antenna," IEEE Trans. Antennas Propagat., vol. 39, pp. 1247-1251, Aug. 1991.

[11] C. Terret, A. Sharaiha, M. Edimo, A. Papiernik, and G. Kossiavas, "Probe-Fed stacked microstrip antennas design and mutual coupling," in Proc. COST 223 ESA Workshop on Active Antennas. Noordwijk, The Netherlands: ESTEC, ESA-WPP 32, June 11-12, 1992, pp. P8.1-P8.5.

[12] E. L. Christensen, "SAR antenna design for ambiguity and multipath suppression," Department of Electromagnetic Systems, Technical University of Denmark, Report R 527, Sept. 1992.

[13] J.E. Hansen and F. Jensen, "Spherical near-field scanning at the Technical University of Denmark," IEEE Trans. Antennas Propagat., vol. AP-36, pp. 734-739, June 1988.

[14] F. Lalezari and R. E. Munson, inventors, "Dual polarized, high efficiency microstrip antenna," United States Patent no. 4.464.663, issued Aug. 7, 1984, filed Nov. 19, 1981

[15] J. Granholm and K. Woelders, "Dual polarization antenna array with very low cross polarization and low side lobes," United States Patent 6.147.648, issued Nov. 14, 2000, priority date April 3, 1996.

[16] K. Woelders and J. Granholm, "Cross-polarization and sidelobe suppression in dual linear polarization antenna arrays," IEEE Trans. Antennas Propagat., vol. 45, pp. 1727-1740, Dec. 1997.

[17] U. H. Gysel, "A new N-way power divider/combiner suitable for highpower applications," in Proc. 1975 IEEE Int. Symp. Microwaves, Palo Alto, CA, pp. 116-118.

[18] H. C. Chappell, "Designing impedance matched in-phase power dividers," Microwave J., vol. 22, no. 2, pp. 51-52, Feb. 1979.

Johan Granholm (M'88) photograph and biography not available at the time of publication.

Kim Woelders photograph and biography not available at the time of publication. 